\title{
DOCUMENTATION, ANALYSIS AND REPRESENTATION OF MODERNIST HERITAGE THROUGH BUILDING INFORMATION MODELING
}

\author{
F. Maietti ${ }^{1, *}$, A. Zattini ${ }^{1}$ \\ ${ }^{1}$ Department of Architecture, University of Ferrara, via Quartieri, 8, 44121, Ferrara, Italy - (federica.maietti, andrea.zattini)@ unife.it
}

Commission II, WG II/8

KEY WORDS: Heritage documentation, Survey and Representation, Modernist Heritage, 3D modelling, BIM, Education

\begin{abstract}
:
The paper is focused on research activities on documentation, analysis and representation of Modernist Heritage in Latin America. The research is part of a broad project developed by the Department of Architecture of the University of Ferrara following the main aim of documentation for knowledge, enhancement and preservation of cultural heritage. In addition to several on site projects developed in cooperation with local institutions, mainly in Brazil, and based on historical analysis, documentation, survey, modelling and diagnostic assessment, the research has then opened up to an in-depth study of Modernist architecture. The field of investigation has been extended to Latin America, through the analysis of the main architectures of the iconic figures of Modernism, in order to collect a database of models as support for different research avenues. The methodological process is based on the "survey of the project", an analysis of documentation as the starting point for the representation in BIM environment from which to extract conventional representations and different levels of interpretation.
\end{abstract}

\section{INTRODUCTION}

The research field focused on Modernist architecture in Latin America has been developed by the DIAPReM Centre (Development of Integrated Automatic Procedures for Restoration of Monuments) of the Department of Architecture of the University of Ferrara in the last years under different scenario. Historical analysis, documentation, survey and representation, diagnostic assessment and joint research have been carried out on different masterpiece of Modernism, in particular in Brazil (Williams, 2009).

The DIAPReM Centre starting from 2013 has developed these research activities focusing on several investigations on Modernist Architectures pursuing the main aim of documentation for knowledge, enhancement and preservation of cultural heritage (Normandin \& Macdonald, 2013).

The researches carried out were developed in cooperation with several Brazilian institutions such as Mackenzie University in São Paulo, FAU USP - Faculdade de Arquitetura e Urbanismo da Universidade de São Paulo, and PUCPR - Pontificia Universidade Catolica do Paranà in Curitiba.

Academic experiences were jointly carried out focusing common researches on documentation, survey and representation of Brazilian heritage in order to improve knowledge and understanding, cataloguing, analyses, enhancement and conservation. Cooperation with local institutions was an important opportunity to work on the possibilities of using 3D survey and modelling as a basis for documenting modernist architecture (Rossato, 2016), often at risk of loss, integrating metric and morphological data with the state of conservation and important information related to architectural features (Balzani et. al., 2018)

Just to mention some of the main outcomes from these on field joints activities, the integrated survey of Casa das Canoas" by Oscar Niemeyer in Rio de Janeiro (Balzani \& Maietti, 2015). The 3D laser scanner survey of FAUUSP building by João Batista Vilanova Artigas was developed within the project of Digital Preservation under a grant from the Getty Foundation (Keeping it Modern Program). This research was aimed at development of a conservation management plan to produce a holistic approach to the maintenance of the building's key features (Balzani et. al., 2017). The integrated digital documentation of Casa de Vidro in São Paulo by Lina Bo Bardi was focused on developing a conservation management plan of the building based on the $3 \mathrm{D}$ survey, digital documentation and diagnostic analysis (Balzani et. al., 2019).

The research on documentation, analysis and representation of Modernist heritage has then opened up to an in-depth study of Modernist architecture extending the field of investigation to Latin America, through the analysis of the main architectures of the masters of Modernism, in order to collect a database of models as support for different research directions.

This advancement in research has led to the development of a methodology based on "indirect" survey, based on the analysis of the available sources and documents as a starting point for the critical analysis and representation of architecture: the survey of the project. This methodology has been developed within the Integrated Course of Surveying II and Techniques of Architectural Representation, Degree Course in Architecture of the University of Ferrara.

The educational experience that integrates this research process has developed over the last five academic years, producing a database with more than 150 models, $90 \%$ consisting of housing (Acayaba, 2011), built between 1928 and 1978 by more than 40 modernist architects.

The methodological process is divided into the following steps (Figure 1):
Research and documentation
Survey of the project
Parametric modelling
Rendering
Scale model
Conceptualization process
Creation of a conceptual model.

The research field of "techniques of representation" opens to a multiplicity of developments for further research and reinterpretations toward a deep knowledge aimed at the enhancement and conservation of Modernist heritage.

\footnotetext{
* Corresponding author
} 


\section{THE OVERALL RESEARCH FRAMEWORK}

The research on documentation, analysis and representation of Modernist Heritage includes Modernist heritage by Oswaldo Bratke, Oscar Niemeyer, Vilanova Artigas, Wladimiro Acosta in Brazil, Luis Barragan in Mexico, Eladio Dieste in Uruguay, Obregón \& Valenzuela and Fernando Martínez Sanabria in Colombia.

Through a methodological path based on survey and representation, which can be defined as "survey of the project", the process of knowledge of the existing heritage building (Parisi et. al., 2019) is faced at geometrical, morphological and constitutive level. Starting from a bibliographic, photographic and iconographic documentation, the building is analysed by identifying geometric and constructive relationships useful for the metric proportioning of the architectural object.

Then the graphic representation begins, first in the form of sketches in order analyse the main features and to better define relevant details of the architecture under analysis, a crucial step since it is a verification method of the virtual model that will be developed.

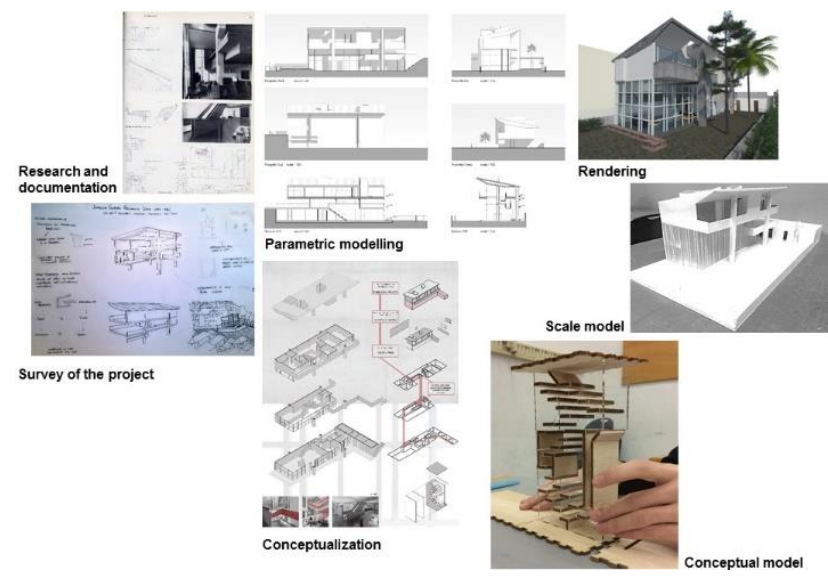

Figure 1. Schematic representation of the main steps of the methodological process: Research and documentation, Survey of the project, Parametric modelling, Rendering, Scale model, Conceptualization process, Conceptual model

The purpose of the three-dimensional representation is to obtain a volumetrically closed and correct object from which to extract architectural drawings such as plans, elevations and sections and through which elaborating photorealistic images (rendering).

The use of BIM (Building Information Modelling) software for architectural modelling, even if purely geometric, allows going through the individual architectural elements and their interactions (Brusaporci et. al., 2018b), particularly on a structural level, with the possibility of defining a level of detail in a second phase.

The use of software that work by mesh or in a non-parametric environment, which would lead to a trivial volumetric reproduction of the elements, facing the level of detail as a "simple" reproduction of the - for instance - decorative features, is limited and avoided. As a matter of fact, the modelling of parametric architectural components requires a deep knowledge of the proportional relationships (López et. al., 2018), the functioning of the element and what the information and its transmission/representation is useful for.

In addition to "conventional" representations, starting from the BIM model it is possible to manage some characteristics (typological, dimensional, contextual, formal, distributive, functional) of the analysed architectures in order to achieve a series of assessments related to both design aspects (proportions, relationship with the context, color and material analysis, etc.) and features related to the main trends of Modernism.

Within the process of digitizing the building through its modelling via software, there are many reasons that are also addressed for those solutions that can be trivial, such as the decoding of architectural language. For instance, identifying if a wall can be interpreted more correctly as a curtain wall or a particular structural element as a beam; the use of the architectural categories to which they belong is an essential aspect.

By proceeding with the building modelling, several "spatial checks" are made by setting similar points of view to the photographs of the built architecture retrieved in the research and study activity, thus defining the first rendering drafts. The photorealistic approach aims to deepen the relationship between volumes and the light and the materials used both indoors and outdoors. Each material is in fact filed and described both in terms of its physical and visual-perceptual characteristics.

\section{APPLIED METHDOLOGY}

Documenting and managing digital data related to existing architectures, which are part of a country's cultural heritage, into a digital database / digital environment requires three different phases: documentation, data management/organization and representation/transmission. The first phase concerns the intellectual approach, related to the knowledge and understanding of heritage, focused on historical research and on architectural survey, followed by the organizational part of "sedimentation" of information into graphic representation, where digital modelling leads to reasoning and evaluation of what was previously learned (Bianchini, 2014). The last step, the transmission of data and information, concerns the representation of the heritage architecture by using technical drawings and graphic simulation or rendering.

The setting up of the research related to documentation, analysis and representation of Modernist Heritage through Building Information Modelling is consistent with the three steps mentioned above. This approach requires preliminary research and documentation both on the building and its designer, information that are collected in a specific form ("Project Form"), up to an extensive digital processing through the use of different software according to different needs of analysis, representation, visualisation.

Regarding the digital aspect of the research, the approach is structured according to a specific procedure. The models are represented using the Revit software, thus obtaining a parametric model populated with information to be appropriately queried and extracted, thus avoiding the use of free form modelling software that would support limited parameters. Furthermore, the choice of using BIM software allows approaching current directions both in research and in the regulatory and application fields, moving away from CAD (Computer-aided Design) systems that are still widely used and, depending on the representative purposes and data management, can have some limitations.

Regarding graphic issues, 3ds Max, specific rendering software, Adobe Photoshop, Illustrator and InDesign are used. This differentiation is part of the overall representation workflow. Furthermore, this software distinction highlights the differences related to raster and vector representation, not only according to the production of printing output but also in order to select the more suitable tool for each objective to be achieved in terms of representation. 


\subsection{First step: documentation}

Through a methodological process of survey and representation, which can be defined as "survey of the project", a process of knowledge at the morphological and constitutive level of an existing building is faced.

The first phase of analysis of the architectures identified within the theme of the architectural heritage of South American Modernism, concerns bibliographic, photographic and iconographic research. All the information found are collected and reported within the Project Form, which describes the designer through a short biography including the main works; the project, to be defined through a representative image, its location and the period of realization; the descriptive and functional relationship of the building. Each source is indicated in the bibliographic list and in the list of references (including web sites, databases and repositories), while photographs and graphic drawings are collected in a sort of documentary database. The step related to the documentation is essential for the knowledge, understanding and interpretation phase related to the modelling and representation step.

\subsection{Second step: data management and organization}

The knowledge and analysis related to the building are critically organized and "settled" through graphic representations, initially in the form of sketches, in order to study the building through the representation of analytical schemes, plans, elevations and sections. This step is crucial; a careful and rigorous hand representation makes it possible to identify any inconsistencies between design documents from multiple sources or photographs taken at different times (Figure 2).
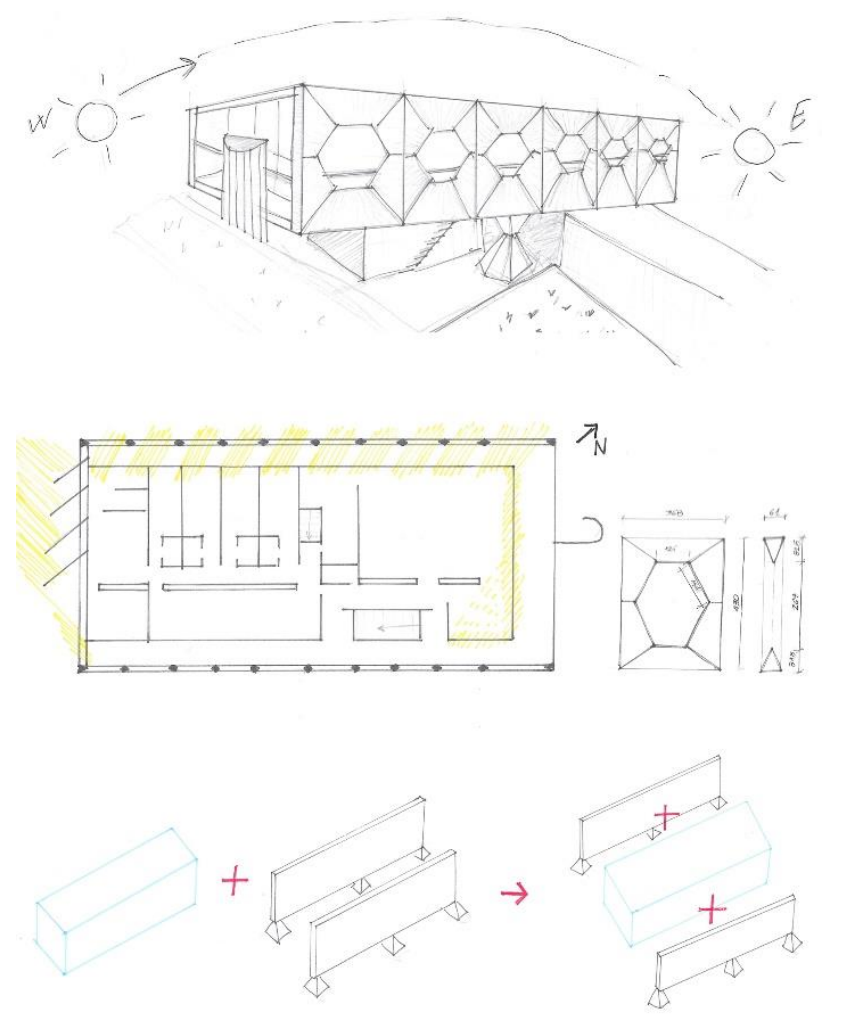

Figure 2. Gama Filgueiras Lima, Residência para Ministro de Estado (1965), Brasília. Volumetric and functional analysis
Furthermore, hand drawing leads to a more in-depth investigation of all the elements that do not find their description within the written texts, sometimes resorting to the analysis of similar architectures of the same designer or of the same architectural movement of the period.

Once this second phase is completed, the dimensional and geometric analysis of the building begins. If dimensional drawings are not available from which it is possible to get the main measures, the procedure foresees identifying key elements, such as the section of particular structures, the width of the doors or the progression of the stairs, of which it is possible to suppose the measure. In any case, every metric information indicated on the reference documents, such as quotas or graphic scales, must be verified and critically checked, also relating plans and sections and comparing different available sources.

The critical approach is indeed essential to resolve any doubts in order to be able to "close" the geometry of the building. Likewise, in the case sources and drawings showing design solutions different from the constructive reality, it will always be the critical approach to guide the composition/representation of the building in the given chosen period, usually focused on the original idea of the designer.

Once the metric proportioning has been identified, both planimetric and altimetric, the digital representation of the architecture begins. This process takes place directly within the BIM architectural modelling software without going through CAD systems, except for some specific limited needs. This approach allows avoiding considering the virtual model as an object after design, used only for rendering purposes.

The purpose of the three-dimensional representation is to obtain an object that is volumetrically closed and correct, or consistent with what has been analysed and assumed from the knowledge phase, from which to extract the architectural drawings such as plans, elevations and sections and through which photorealistic images can be processed (rendering) (Figure 3).
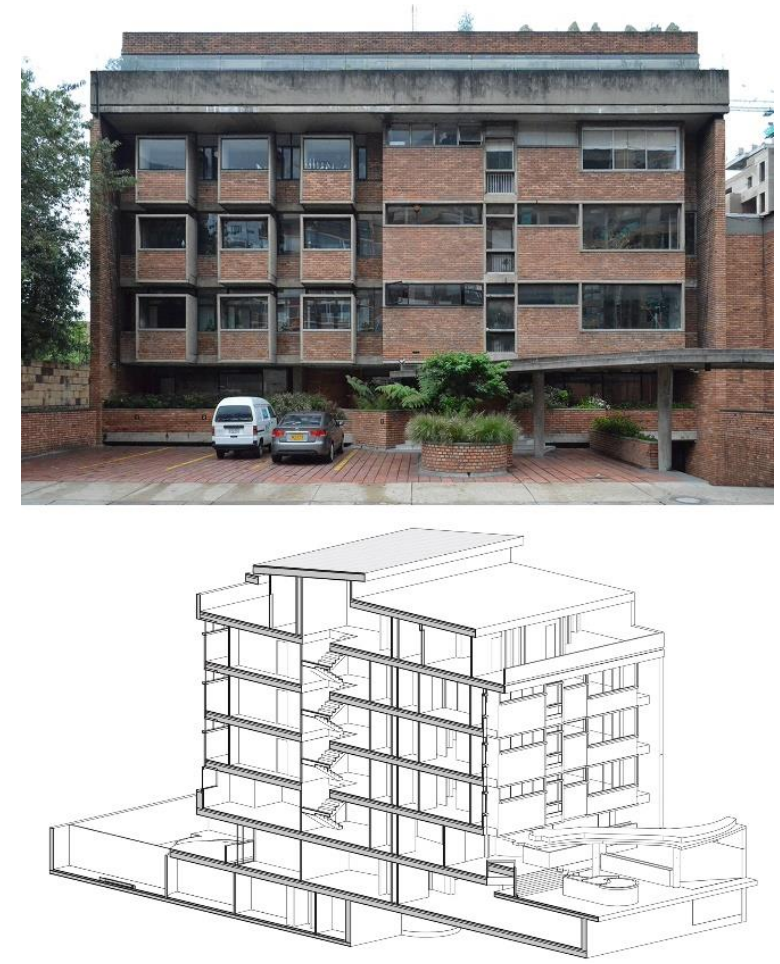

Figure 3. Fernando Martìnez Sanabria, Edificio Giraldo (1958), Bogotà. View of the built architecture (on the top) and axonometric cross-section 
Despite the purely geometric modelling of the building, the use of BIM software for architectural modelling provides the possibility of reasoning in-depth about the single elements at the constitutive level and, in particular at the structural level, about the interaction between the different parts (Brusaporci et. al., 2018a). Even the simple alignment between elements, which often appears obvious in the two-dimensional analysis, leads the modeller to activate a spatial approach and then review what has been hypothesized in the study phase.

The lack of specific constitutive elements of the architectural elements is not to be considered decisive in the choice of the software or of the 3D modelling methodology; the geometric representation fits perfectly in the early stages of the building construction cycle (entirely manageable through BIM) (Osello et. al., 2016). Furthermore, when operating on existing buildings it is not always possible to get to know the stratigraphic composition of the structural elements and the increase in LOD (Level of Detail) is also possible at a later time.

The use of software that works by mesh or in a non-parametric environment, which would lead to a trivial volumetric reproduction of the elements addressing the level of detail as aseptic reproduction of any decorative element, is limited or avoided.

This allows a more similar approach to the BIM dynamics by identifying the most effective solution for the transmission of the necessary information (Bianchini et. al., 2016), avoiding the hypermodelling that would produce high quantities of points that would not benefit any exchange of calculations. Furthermore, the two-dimensional graphics should not be neglected, which belongs entirely to the software, which can be managed according to the LOD and the scale of representation.

The parametric modelling of architectural components leads to think about proportional relationships, the functioning of the element and what are the useful information and their transmission.

Within the process of digitization of the building in its software modelling there are many arguments that are also addressed for those solutions that may be trivial, such as the decoding of architectural language. In fact, defining whether a wall can be more correctly interpreted as a curtain wall or whether the uprights of a particular structure are more correct as beams, must not lead to the identification of the easiest solution but to analyse the constructive reality. The use of the architectural categories to which they belong is an essential aspect.

Inside the modelling process the peculiar components of the building are realized, such as doors and windows characterized by a particular design. Also, the modelling of these elements is parametric trying to elaborate adaptable elements at least as regards the general dimensioning.

Once the building is volumetrically complete, a series of spatial checks were carried out. These checks are carries out by setting up points of view corresponding to the photographs found in the research activity. The comparison highlights any possible inconsistencies, and also allows defining the first drafts of rendering.

\subsection{Third step: transmission}

The last phase concerns all the aspects of communication of the project and its representation, consisting mainly of architectural drawings and photorealistic renderings, and two physical models, one realistic in scale and one of a "conceptual" nature. While the scale model allows controlling the space and helps to understand the articulation between the components of the building, the conceptual model has the function of materializing the essential work of analysis and interpretation. A part of the representation is indeed focused on the conceptualization of the main meanings
(Balzani \& Maietti, 2017) extrapolated from the analysed architecture.

From the BIM model, the architectural drawings are then extracted such as plans, elevations, sections, axonometric, crossaxonometric views (Figure 4) and exploded axonometric views. For these drawings, graphic standards are provided to be achieved through the management of line thicknesses and visualization style based on the representation scale. However, the layout of the representations does not take place in the BIM software but in the Adobe InDesign program, in order to guarantee more flexibility and freedom in the management of graphics that does not come from the use of a single software.

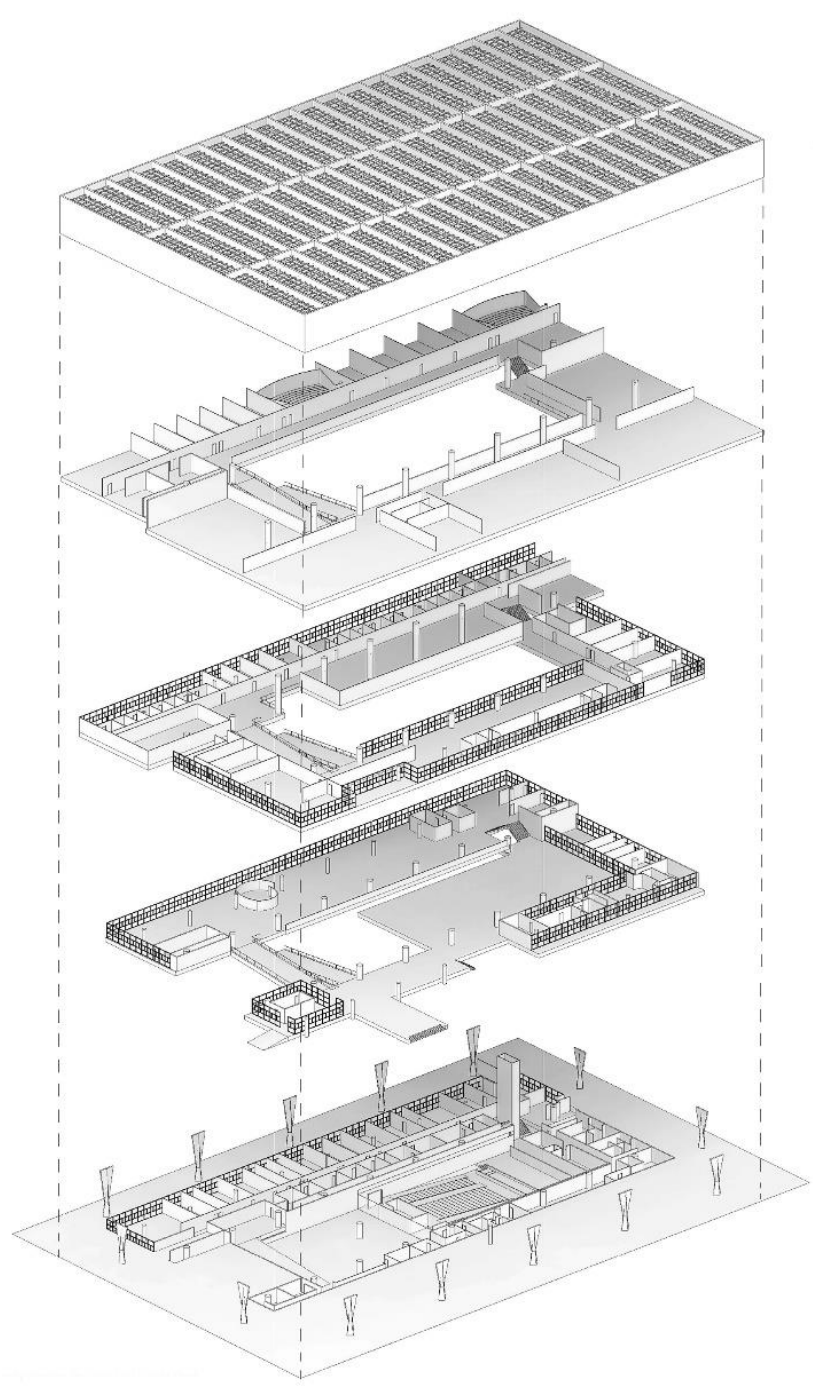

Figure 4. Villanova Artigas, FAUUSP (1953), Sao Paulo. Exploded axonometric view

The representation of digital images, which involves the connection of the BIM model within the $3 \mathrm{ds}$ Max rendering software, is performed at a photorealistic level. This approach aims to deepen the relationship of architectural volumes with light and the behaviour of materials used both internally and externally, also analysing the photographic documentary material of the project, avoiding therefore images elaboration altering the perception of the reality, characterized by persuasive and misleading graphics (Figure 5) (Nastasi, 2016). Each material is in fact filed and described both in terms of its physical and visual- 
perceptive characteristics, so as to define all the maps to be associated with the different descriptive parameters, such as reflection, refraction, glossiness, translucency, opacity, bump and displacement, which are in most cases processed ad hoc on Photoshop. Still on this last software, the previously processed images are further processed through a post-production process for the insertion of the context and possibly of human figures (Figure 6).

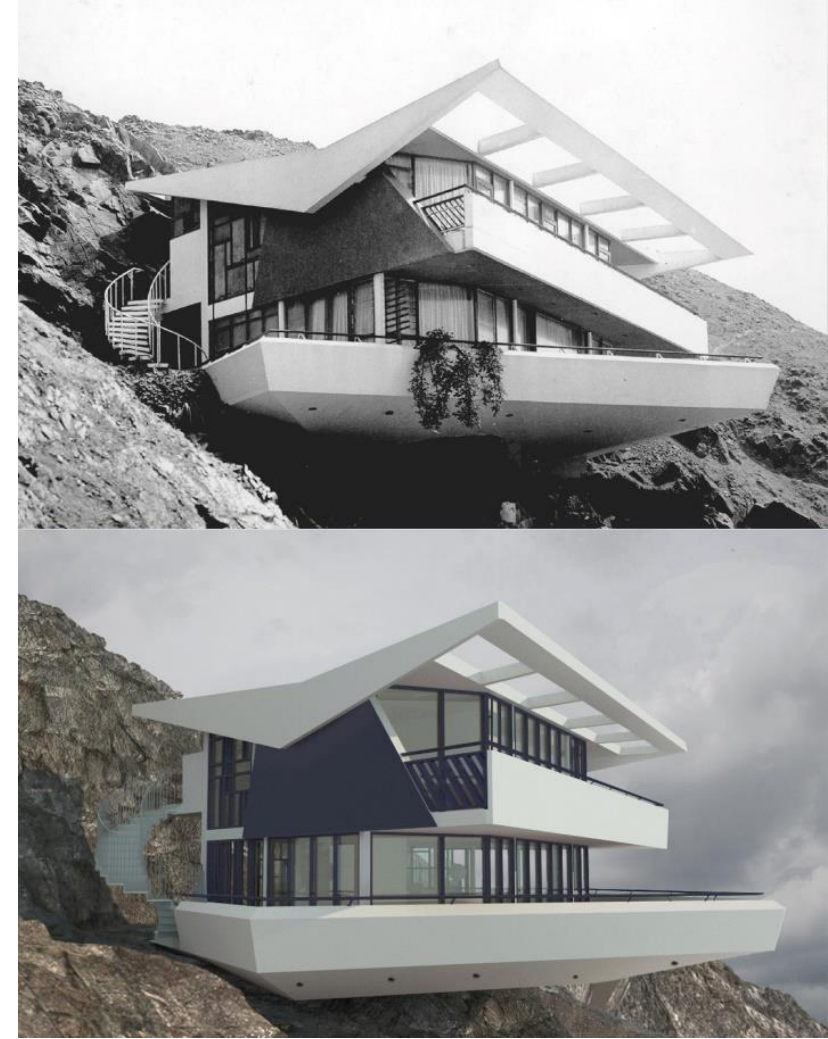

Figure 5. Walter Weberhofer, Fernandini house (1958), Lima. On the top, historical photo retrieved during the research and analysis phase, and, on the bottom, exterior rendering

\subsection{Educational and training experiences}

The above-mentioned approach to the documentation, analysis and representation of Modernist Heritage through Building Information Modelling has been developed also through several research and educational experience arisen through $\mathrm{PhD}$ Courses, international workshops and training experiences. In particular, within several editions of the integrated course of Surveying II and Techniques of Representation at the Department of Architecture of the University of Ferrara, the overall process has been tested and the students had the opportunity to deepen the experience of the survey of the project, parametric modelling and photorealistic representations applied to Modernist architecture. The teaching experience is organized by dividing the students into groups of three people and assigning each group an architecture belonging to the Modernism in Latin America.

Students then immediately begin the phase of study, research and analysis of architecture, guided by specific lectures that have the task of framing the cultural approach.

Then the "survey of the project" begins, according to the procedure described above. The first step is related to the graphing through sketches, verifying that the information found in the research phase is sufficient to describe the architecture in its entirety and to represent it. An important aspect of the critical approach is related to the interpretation of the architecture in the context of the architect's global production and the main pillars of the cultural movement.
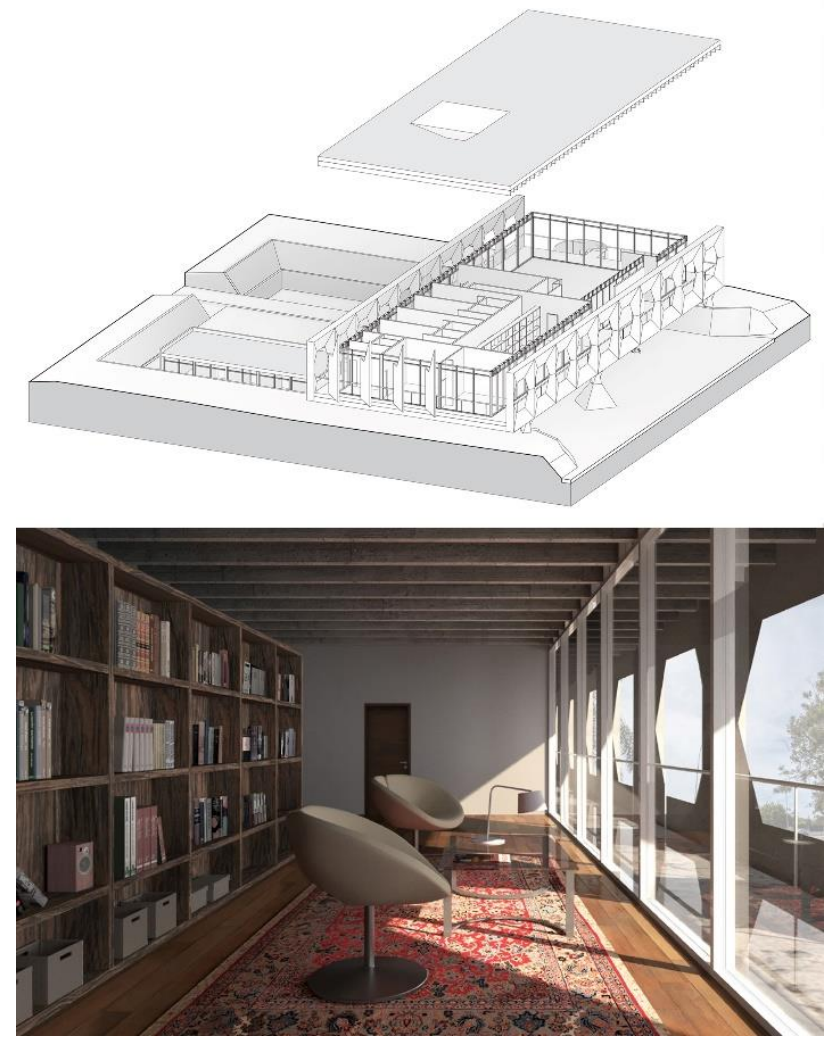

Figure 6. Gama Filgueiras Lima, Residência para Ministro de Estado (1965), Brasília. Axonometric view and interior rendering

The analysis and interpretation phase is not only the essential support to the overall representation, but also to the production of the conceptual representation required in addition to the "conventional" drawings.

Within the course, to facilitate the learning of the different software, a series of exercises are organized both in the classroom and at home. These practice exercises are focused on parametric modelling, both of multi-storey buildings and architectural components such as windows, photorealistic renderings, postproduction of digital images for the contextualization of the project (Figure 7), layout of contents in graphic works for "paper space" management and reading effectiveness of the panel layout where drawings are organized.

Once the proportioning and the dimensional assessment is completed, the digital representation of the assigned architecture begins, directly within the BIM architectural modelling software. This choice allows students to get closer to the potential of BIM digital systems, being able to experience the most immediate advantages in terms of speed and ease of modification and updating of the digital model, and avoiding considering the virtual model as a mere post-design object, used only for rendering purposes. 

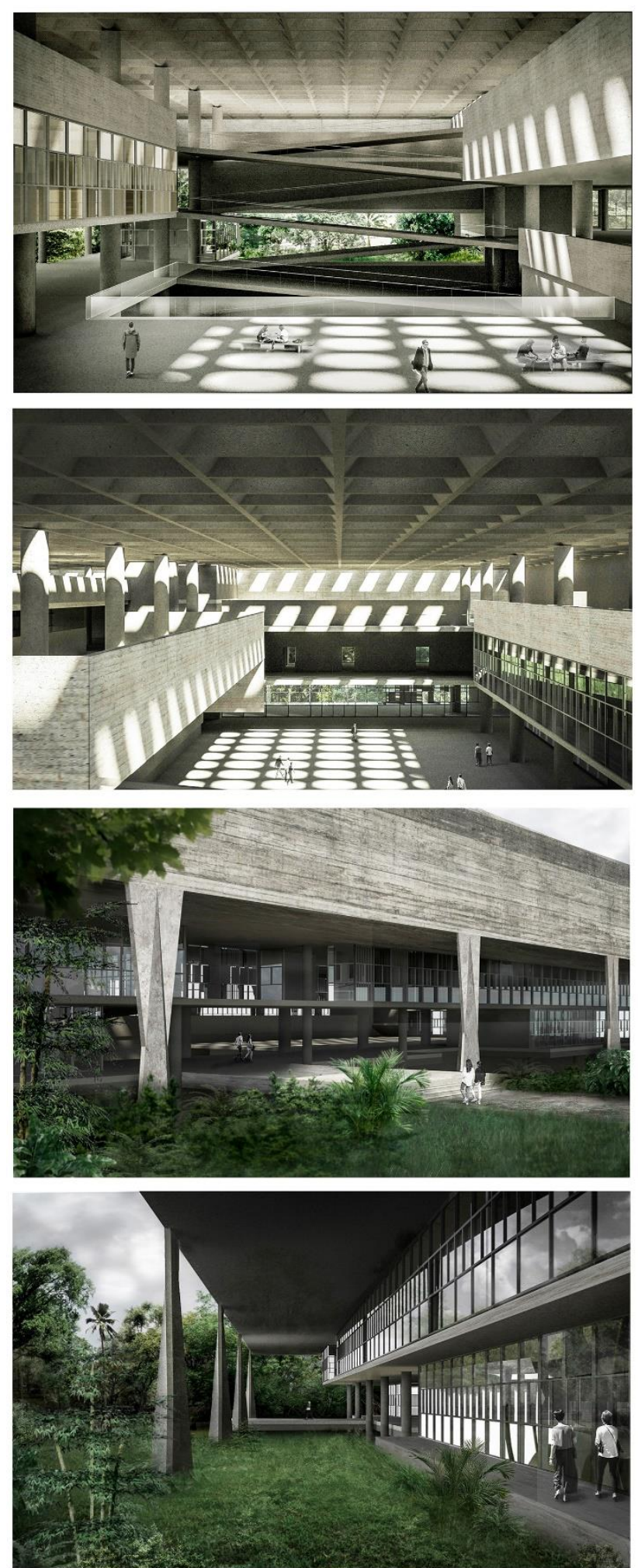

Figure 7. Villanova Artigas, FAUUSP (1953), Sao Paulo. Interior and exterior renderings

Within the modelling process the peculiar building components are realized, such as doors and windows characterized by a particular design. Also the modelling of these elements is parametric trying to elaborate adaptable elements at least as regards the general dimensioning. For particularly complex elements to be dealt with within the educational path, instead, the process is limited to a local modelling or otherwise generally not editable at the project level.

The last step concerns all the aspects of communication of the project (Vernizzi, 2017) through the creation of graphic works, consisting mainly of architectural drawings and photorealistic renderings to be presented within three large-format panels, and two physical models, one realistic in scale and a conceptual one. Moreover, since the collection of the documents in the panels takes place at the end of the course, the groups are given a preset layout useful for the final presentation. For this reason, the layout of the panels is dealt with through a mid-term workshop, where students create a medium format summary panel starting from the analysis of a project where all the drawings have to find space in a clear architectural narrative.

While the first two panels summarize the parametric modeling and the extraction of architectural drawings, and the photorealistic representation, the third panel focuses on the conceptual aspect, or on the suggestion that the in-depth analysis of the architecture has communicated to the work group (Figures $8,9)$. In this case, the layout is freer in order to be able to arrange freely processed images, as long as they are consistent with the materialization of the concept in the form of a physical model.

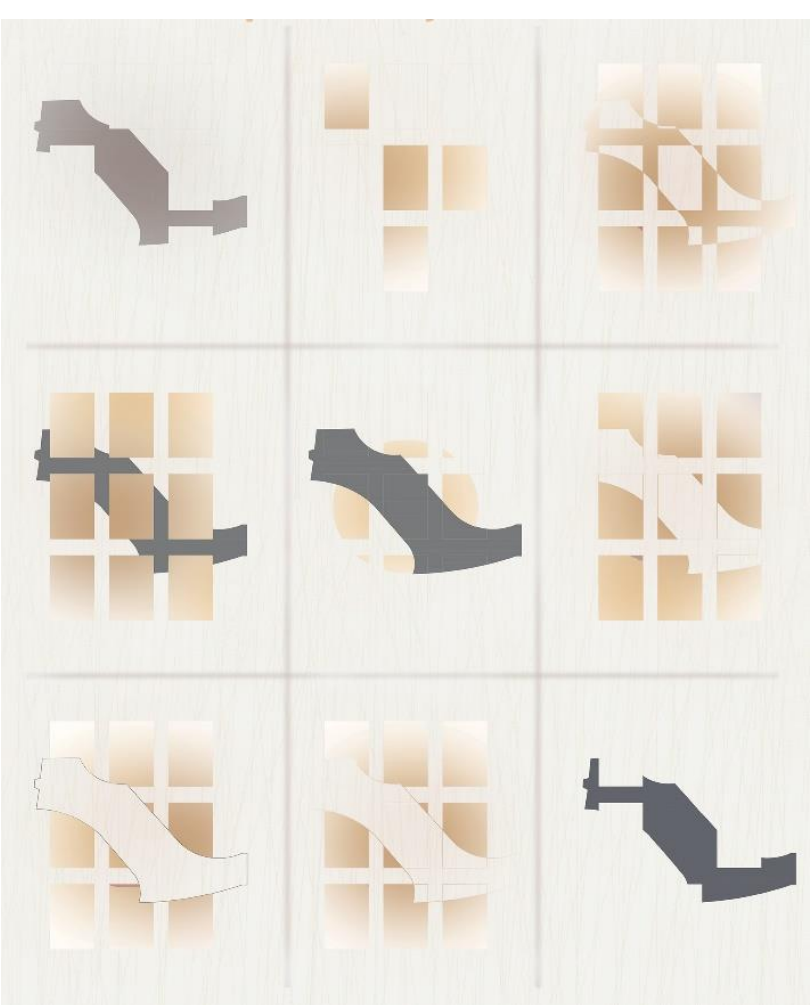

Figure 8. Fernando Martinez Sanabria, Residenza Giraldo (1958), Bogotà. Project conceptualization starting from the architecture' shape

While the realistic model in scale, usually in a 1:100-dimensional scale, is expressly requested in wooden material, the conceptual one is the result of a creative knowledge process produced by the students, and the choice of materials and of any interaction mechanisms is agreed and followed by the teachers. In fact, models based on mechanical behaviours with which the observer 
can interact are quite frequent, creating models set up as a stimulating game (Figure 10).

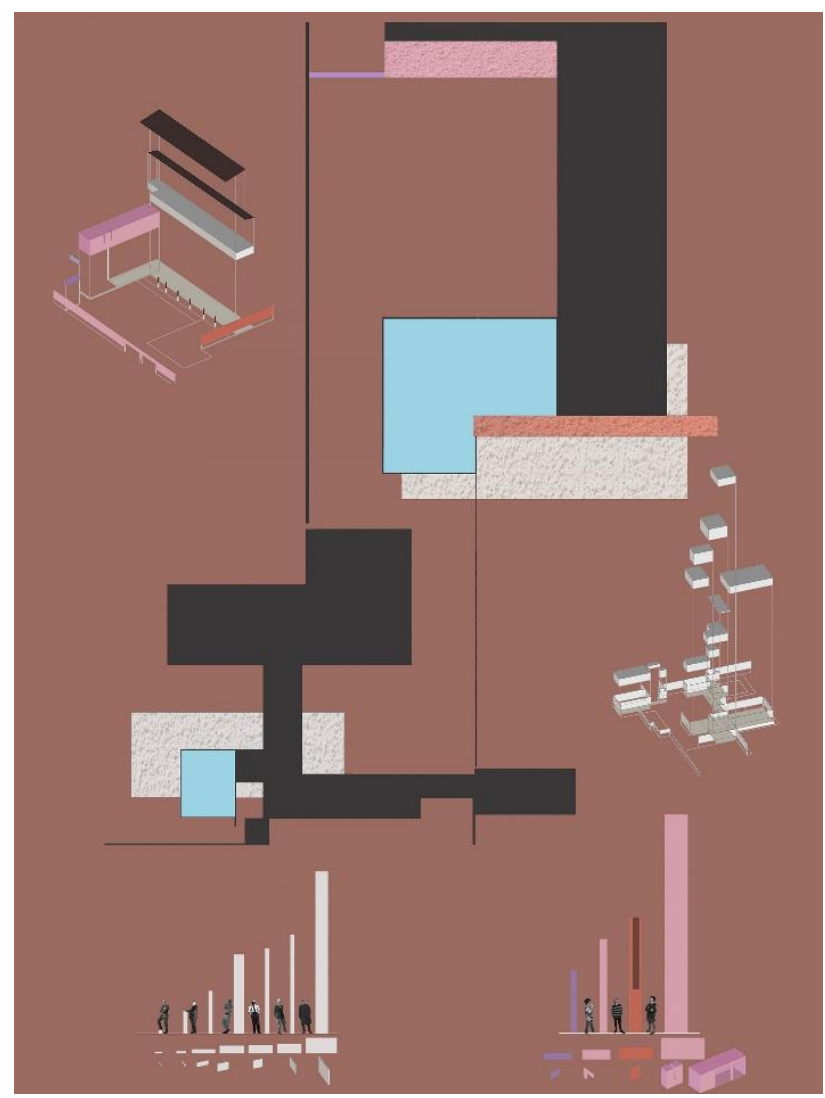

Figure 9. Luis Ramiro Barragán Morfín, Cuadra San Cristobál (1968), Atipazan, Messico. Project conceptualization

\section{CONCLUSION}

The outcomes of the research methodology and of the didactic strategies are not limited to "describing" an existing architecture from what it looks like but tries to express its design features (Spallone, 2016). The BIM model collects volumetric-spatial information and design features linked to the individual parametric components, graphically expressed and enriched by the experience of study and conceptualization.

Therefore, what is to be highlighted is the resulting working method that integrates the definition of an existing architectural object through its indirect study to a "preliminary" design phase, that is a low LOD (Level of Development), which nevertheless includes a very high level of knowledge of the building (Osello et. al., 2015).

The research steps and the skills developed by the students allow having broad bases on which they can continue their studies deepening and specifying the various aspects related to modelling and representation (Rossato, 2017). In particular, the geometric modelling carried out through the use of BIM is in an effective approach to the use of such systems, especially within a context rich of heritage such as the Italian one, characterized by different complexities that is still difficult to deal with in parametric environment. The use of a digitalisation method, however simplified and aimed at setting up a database with documentary purposes, which starts from a careful analysis and research, is therefore essential.
The use of BIM systems in a context rich in pre-existences, such as the Italian one (Sdegno, 2017), is daily and the adoption of recent regulations, both European and national, requires this approach when working in the public and therefore, even more so, on heritage. The exercise of using a digitization method, which starts with careful analysis and research, is essential within education activities related to survey and representation for new generations.

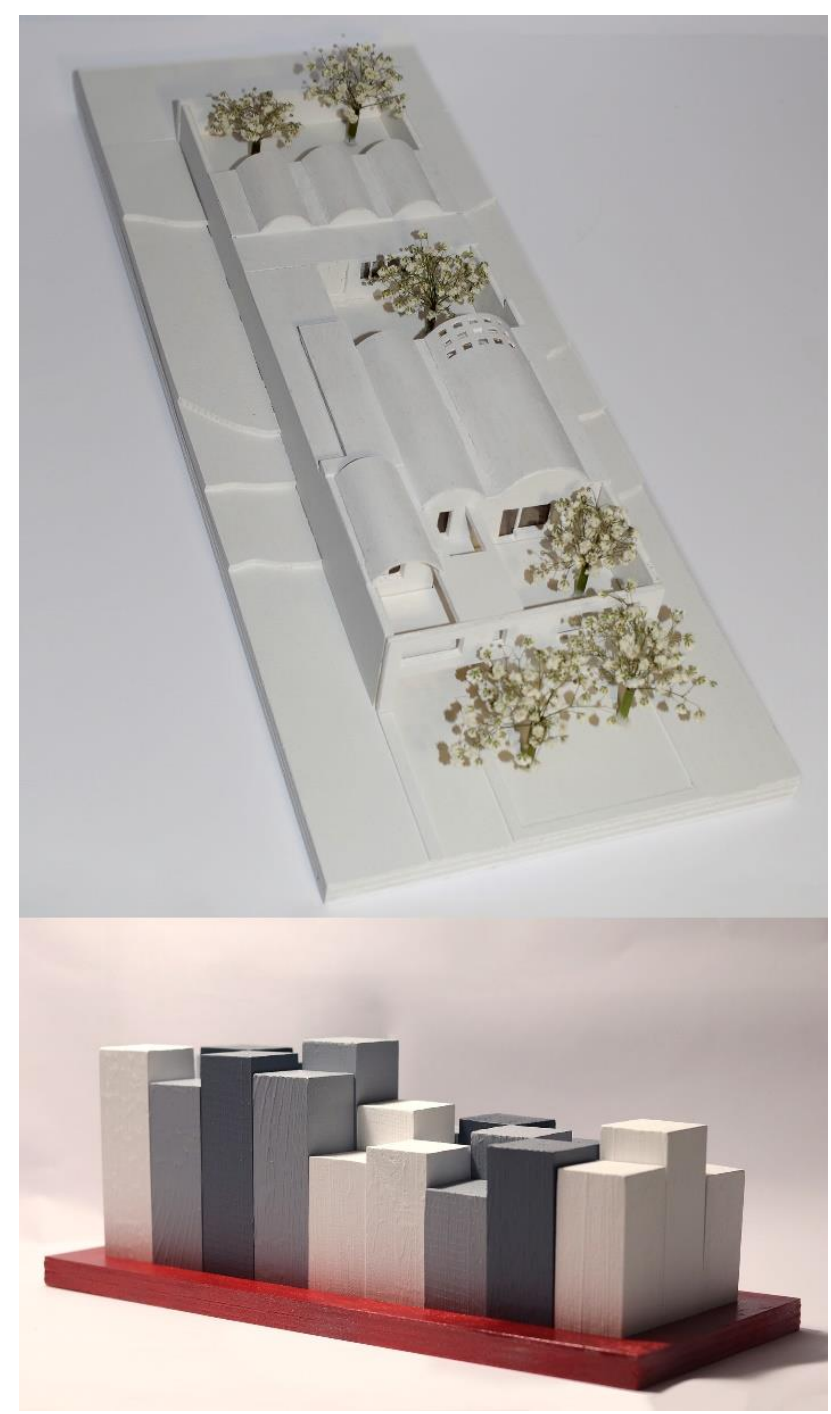

Figure 10. Eladio Dieste, Casa Eladio Dieste (1961)

Montevideo. Realistic scale model (above) and its related conceptual model

\section{ACKNOWLEDGEMENTS}

Research on Modernist Architecture in Brazil and Latin America have been developed by the DIAPReM center of Department of Architecture, University of Ferrara, even though PhD Courses, international workshops, and educational and training experiences. The outcomes described in this paper are part of activities carried out within the integrated course of Surveying II and Techniques of Representation, Department of Architecture, University of Ferrara, AA 2018-2019, Professors Federica Maietti and Andrea Zattini under the scientific supervision of Marcello Balzani. 


\section{REFERENCES}

Acayaba, M., 2011. Residências em São Paulo: 1947-1975. Romano Guerra Editores, São Paulo.

Balzani, M., Maietti, F., 2017. From the survey of the project to representation: geometrical-conceptual analysis of the architecture of the twentieth century between teaching and research. In: Territories and Frontiers of Representation, Gangemi Editore, Roma, pp. 1225-1232.

Balzani, M., Maietti, F., 2015. Integrated methodologies for documentation and restoration of Modern architecture: survey and representation of the "Casa das Canoas" by Niemeyer. In: Gambardella, C. (Ed.), Heritage and Technology. Mind Knowledge Experience, La scuola di Pitagora editrice, Napoli, pp. 878-887.

Balzani, M., Maietti, F., Mugayar Kühl, B., 2017. Point Cloud Analysis for Conservation and Enhancement of Modernist Architecture. The International Archives of the Photogrammetry, Remote Sensing and Spatial Information Sciences, Volume XLII2/W3, pp. 71-77.

Balzani, M., Maietti, F., Rossato, L., 2019. 3D Data Processing Toward Maintenance and Conservation. The Integrated Digital Documentation of Casa de Vidro. The International Archives of the Photogrammetry, Remote Sensing and Spatial Information Sciences, Volume XLII-2/W9, pp. 65-72.

Balzani, M., Maietti, F., Rossato, L., 2018. Research activities on Brazilian Cultural Heritage: a cooperation net in the field of technologies for survey and representation. In Bertocci S. (Ed.), Conference Proceedings of Symposium of Representation Scientific Area for development of Multidisciplinary International Programs, didapress, Firenze, pp. 60-65.

Bianchini, C., 2014. Survey, Modelling, Interpretation as Multidisciplinary Components of a Knowledge System. SCIRESIT-SCIentific RESersch and Information Technology, vol. 4, Issue $1,15-24$.

Bianchini, C., Inglese, C., and Ippolito, A., 2016. The role of BIM (Building Information Modeling) for representation and managing of built and historic artifacts. Disegnarecon, 9(16), 101 .

Brusaporci, S., Maiezza, P., and Tata, A., 2018a. A Framework for Architectural Heritage HBIM Semantization and Development. International Archives of the Photogrammetry, Remote Sensing and Spatial Information Sciences, vol. XLII-2, pp. 179-184.

Brusaporci, S., Maiezza, P., and Tata, A., 2018b. Computational Design for As-Built Modeling of Architectural Heritage in HBIM processes. In: IEEE International Workshop on Metrology for Archaeology and Cultural Heritage. IEEE Institute of Electrical and Electronics Engineers, 2018. pp. 194-198.

López, F., Lerones, P., Llamas, J., Gómez-García-Bermejo, J., and Zalama, E., 2018. A review of heritage building information modeling (H-BIM). Multimodal Technologies and Interaction, 2(2), 21.
Nastasi, M., 2016. The City of Renderings. Photorealism, Spectacle and Abstraction in Contemporary Urban Landscapes. In: Alcolea R.A. and Tárrago Mingo J. (Eds.), Proceedings of the Inter-Photography and Architecture International Conference, Pamplona, November 2nd-4th, 2016. Pamplona: Universidad de Navarra, pp- 274-285.

Normandin, K. and Macdonald, S., 2013. A Colloquium to Advance the Practice of Conserving Modern Heritage. The Getty Conservation Institute, Los Angeles.

Osello, A., Davardoust, S., Semeraro, F., Lucibello, G., Barone, L., Dellosta, M., Ronzino, A., Del Giudice, M., Fonsati, A., De Luca, D., Ugliotti, F.A., and Rapetti, N., 2016. The centrality of Representation with BIM. Disegnarecon, 9(16): 5-1-5.12

Osello, A., Acquaviva, A., Dalmasso, D., Erba, D., Del Giudice, M., Macii, E., and Patti, E., 2015. BIM and Interoperability for Cultural Heritage through ICT. In Handbook of Research on Emerging Digital Tools for Architectural Surveying, Modeling, and Representation, IGI Global, pp. 274-291.

Parisi, P., Turco, M. L., \& Giovannini, E. C., 2019. The Value of Knowledge through H-BIM Models: Historic Documentation with a Semantic Approach. International Archives of the Photogrammetry, Remote Sensing and Spatial Information Sciences, 42(2/W9), pp. 581-588.

Rossato, L. 2016. Digital Tools for Heritage Preservation and Enhancement. In: Euro-Mediterranean Conference. Springer, Cham, pp. 567-578.

Rossato, L., 2017. Digital Toolkit for the Representation, Survey, Preservation and Enhancement of 20th Century Buildings in Brazil and India. In: Multidisciplinary Digital Publishing Institute Proceedings, Vol. 1, No. 9, p. 858.

Sacchi, L. A., 2016. ON BIM. Disegnarecon, 9(16), 1.1-1.8.

Sdegno, A., 2017. Recent Italian Events on BIM. diségno, 1(1 e 2), 180-183.

Spallone, R., 2016. Re-drawing Architecture for Exploring the Design. From Research to Teaching and Vice Versa. In: Congreso Internacional de Expresión Gráfica Arquitectónica, Springer, Cham, pp. 983-994.

Vernizzi, C., 2017. The three-dimensional drawing of architecture, between tradition and innovation, as an expression of creativity and tool foreshadowing and communicating the project. In: Territories and Frontiers of Representation, Gangemi Editore, Roma, pp. 13-20.

Williams, R. J., 2009. Brazil: Modern Architectures in History. Reaktion books, London. 